UDC 541.64

DOI: $10.33184 /$ bulletin-bsu-2021.1.12

\title{
STUDY OF RHEOLOGICAL PROPERTIES OF AQUEOUS PECTIN SOLUTIONS
}

\author{
(C) M. A. Afanasieva, M. Yu. Lazdina, A. S. Titlova, E. I. Kulish*
}

Bashkir State University

32 Zaki Validi Street, 450076 Ufa, Republic of Bashkortostan, Russia.

*Email: onlyalena@mail.ru

The study is devoted to the rheological behavior of aqueous solutions of pectin, a natural polysaccharide, which is a polyelectrolyte and has a spectrum of physiological activity. It is shown that the polyelectrolyte nature of the polymer introduces significant features into its rheological behavior. These features are manifested in the form of low values of the activation energy of viscous flow, in the absence of an anomaly in the viscous flow of solutions above the crossover point, as well as in the existence of a concentration region in which macromolecules are in contact with each other, but do not form a fluctuation network of meshes.

Keywords: polymer, polyelectrolyte, viscosity, rheological properties, fluctuation network, concentration of crossover.

\section{Introduction}

The research of rheological characteristics of polymer solutions is of great theoretical and practical interest. The theoretical interest is due to the fact that the dependence on viscosity on shear rates, strain, and the concentration of polymers in solutions, the temperature of the process can result in the conclusion about its structural and physical conditions [1-2]. The practical interest is conditioned by the fact that polymer's viscosity and its anomalies define the conditions of polymer processing [3-4].

The rheology of nonionic polymer solutions has a long history and is well studied [5-9]. For these solutions the boundary of concentration regimes of polymer solutions is clearly defined. The role of this boundary plays the crossover point that is defined as the concentration of solutions at which the overlapping of macromolecular coils and the formation of a network of meshes begins [1]. The crossover point characterizes the transition of the regime from the diluted to semi-diluted solutions and change in the mechanism of mass transfer of macromolecules. In the diluted area the translational mechanism of mass transfer is realized, in the semidiluted area the reptational mechanism is realized [6].

The rheological behavior of polyelectrolytes is less studied. The presence of electrostatic repulsion between polymer ions can affect both the value of the crossover point and the formation of the mesh of entanglements [10-15]. Unfortunately, the experimental data on the study of the rheological properties of polyelectrolyte solutions are currently insufficient to draw unambiguous conclusions about the mechanism of the change in concentration regimes. In this regard, the aim of this work was to study the rheological behavior of aqueous solutions of pectin, a natural polysaccharide, which is a polyelectrolyte and has a spectrum of physiological activity [16-17].

\section{Experimental}

The object of the research is pectin (PC) of citrus origin produced by SIGMA-ALDRICH. The character- istic viscosity was defined using Ubelode viscometer and calculated using the Baranov's method [18], which makes it possible to exclude the influence of the polyelectrolyte swelling effect on the intrinsic viscosity. According to this method, the value of $\frac{\partial \ln \left(\eta_{\text {relative }}\right)}{\partial c}$ at each point of the dependence of $\ln \eta_{\text {relative }}$ on the polymer concentration in solution $C$ can be considered as the current value of the intrinsic viscosity:

$$
[\eta]^{*}=\frac{\partial \ln \left(\eta_{\text {relative }}\right)}{\partial C},
$$

where $\eta$ relative is the value of relative viscosity of polymer solutions. It is obvious that with $C \rightarrow 0$ the value of $[\eta]^{*}$ corresponds to the initial slope of the dependence of $\ln \eta_{\text {relative }}$ on $C$ and coincides with the value of the intrinsic viscosity [ $\eta]$ which describes the behavior of an isolated macromolecule.

Rheological measurements of aqueous solutions of PS were carried out on a Haake Mars III modular dynamic rheometer at $25 \pm 1{ }^{\circ} \mathrm{C}$ in an oscillatory mode. Since tests in the oscillatory mode must be performed in the area of linear viscoelasticity, initially, based on the dependences of the storage modules and losses on the stress amplitude obtained at a constant oscillation frequency, the optimal amplitude values corresponding to constant values of the modules (linear viscoelastic region) were determined. For PC solutions in the interval from 0.05 to $20 \%$ in the range of amplitudes from 0.1 to $10 \mathrm{~Pa}$ and oscillation frequencies from 0.1 to $10 \mathrm{~Hz}$, the solution corresponded to the region of linear viscoelasticity, since the values of the modules did not depend on the voltage amplitude. The activation energy of viscous flow of the studied systems $E_{a}$ in the temperature range from 15 to $80{ }^{\circ} \mathrm{C}$ was estimated using the Arrhenius-Frenkel-Eyring equation (2) and calculated by the least squares method:

$$
\eta=\mathrm{A} e^{\Delta E_{a} / R T}
$$

where $\mathrm{R}$ is the universal gas constant, $\mathrm{A}$ is the preexponential factor.

\section{Results and discussion}

It is known that polymers in solutions can exist in different concentrate modes $[1-2 ; 5]$. In the regime of 
diluted solutions with the concentration of $C$ less than the concentration of crossover $C^{*}=1 /[\eta]$, where $[\eta]$ is the intrinsic viscosity, macromolecules of nonionic polymers are isolated from each other. They do not interact with each other, and the viscosity of the solution increases with an increasing concentration according to the linear law $\eta \sim C^{\delta}$, where $\delta=1.00$.

In this area of concentration in the rheological point polymer solution behaves like newton liquid the viscosity of which doesn't depend on shear rate or oscillation frequency.

At the concentration of $C$ greater than $C^{*}$ macromolecules interact with each other and the viscosity depends on the concentration according to the power law $\eta \sim C^{\delta}$, where $\delta>1.00$. At the same time, upon going to the region of semi-diluted solutions, the nature of the dependence of viscosity on the shear rate changes, namely, the viscosity of polymers decreases with an increase in the shear rate (or oscillation frequency), i.e. solutions of nonionic polymers behave in the overwhelming majority of cases as a pseudoplastic liquid.

The increase in the concentration is accompanied by formation of the network of meshes with the concentration of $C_{\mathrm{e}}$ that can be easily defined at the beginning of a sharp increase in viscosity. A sharp increase in the intensity of viscosity growth is due to the fact that, upon going from a diluted solution to a semidilute solution, the mass transfer mechanism changes (from translational to reptational), which is associated precisely with the formation of a fluctuation mesh of entanglements [6].

However, the rheological behavior of polyelectrolytes has its own features. For example, in nonionic solutions the fluctuation network of meshes is formed almost immediately after reaching the crossover point. Respectively, the value of $C^{*}$ coincides with the value of $C_{e}$. However, in the nonionic solutions there is electrostatic repulsion of like-charged chains, which can prevent the coils from penetrating into each other and the formation of a network of meshes. Therefore, in the solutions of polyelectrolytes there can be the area of semi-diluted solutions in which coils touch each other, but do not form the network of meshes. The presence of such an area is discussed, for example, in [19-23].

Indeed, a sharp increase in the dynamic viscosity of PC solutions and the transition from one concentration regime (diluted solution) to another (semi-diluted) occurs not at a crossover concentration with $C^{*}=1 /[\eta]$, but somewhat later (fig. 1).

As it is seen from the data in fig. 1, in the temperature range $15-80{ }^{\circ} \mathrm{C}$, the concentration of the formation of the network of meshes $C_{e}$, determined by the onset of a sharp increase in viscosity, corresponds to a solution with a concentration of 2.5-3.0 g/dl. Considering that the values of intrinsic viscosity that were determined using Baranov's method are $[\eta]=5.0 \mathrm{dl} / \mathrm{g}$ at $20{ }^{\circ} \mathrm{C}$ and $[\eta]=4.8 \mathrm{dl} / \mathrm{g}$ at $80{ }^{\circ} \mathrm{C}$, the crossover point with $C^{*}=1 /[\eta]$ for these polymers corresponds to concentrations of 0.2 and $0.21 \mathrm{~g} / \mathrm{dl}$, respectively. As it is seen from the data in fig. 1, reaching the crossover point does not affect the polymer flow mechanism. In this regard, we can speak about the presence of a transition region from a diluted region to a semi-diluted region, in which the macromolecules contact with each other, but do not form the network of meshes. It is obvious that in transition area with an increase in concentration there is a gradual compression of macromolecular coils due to their contact and overcoming the forces of electrostatic repulsion. Only after this the network of meshes forms in the system.

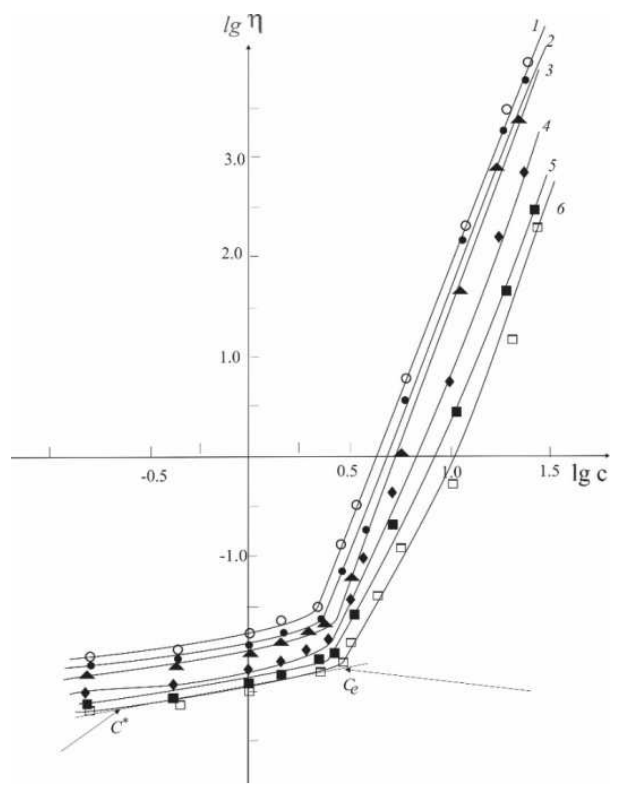

Fig. 1. Concentration dependence of complex viscosity at a temperature of $15(1), 20(2), 30(3) 40(4), 60(5)$ and $80(6){ }^{\circ} \mathrm{C}$ for pectin solutions. 
The difference in the rheological behavior of the polyelectrolyte solution is also evidenced by the shape of the viscosity curves (fig. 2). As it is known, when testing polymer solutions in the oscillation mode the dependence of the viscosity on angular velocity (oscillation frequency) is studied. As we can see from the data in fig. 2, the pectin solutions with the concentration $2 \mathrm{~g} / \mathrm{dl}$ in the temperature range from 15 to $80{ }^{\circ} \mathrm{C}$ behave like newton liquids, i.e. their viscosity range does not depend on the oscillation frequency (fig. 2, curves $1-5$ ). The pectin solution with the concentration of $5 \mathrm{~g} / \mathrm{dl}$ in the temperature range from 40 to $80{ }^{\circ} \mathrm{C}$ behaves like newton liquids (curves 6-7), but the decrease in temperature below 30 (curves 8-10) results in a typical (for pseudoplastic fluids) change in viscosity with the oscillation frequency, namely, the viscosity decreases with the oscillation frequency.

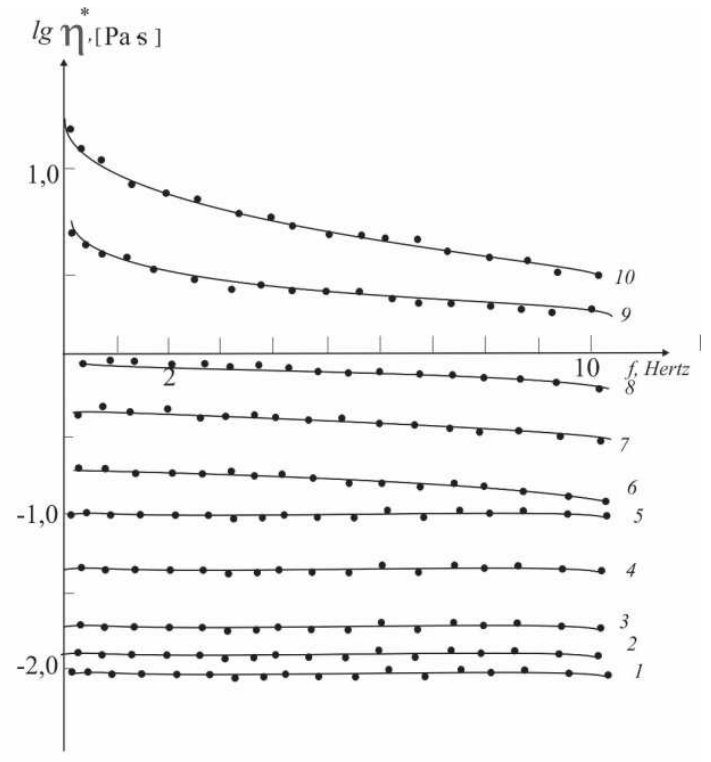

Fig. 2. Dependence of the complex viscosity on the oscillation frequency for pectin solutions of concentration $2(1-5), 3(6,7)$ and $5 \mathrm{~g} / \mathrm{dl}(8-10)$ at a temperature of $80(1,6), 60(2)$,

$40(3), 30(6,8), 20(4,7,9), 15^{\circ} \mathrm{C}(5,10)$.

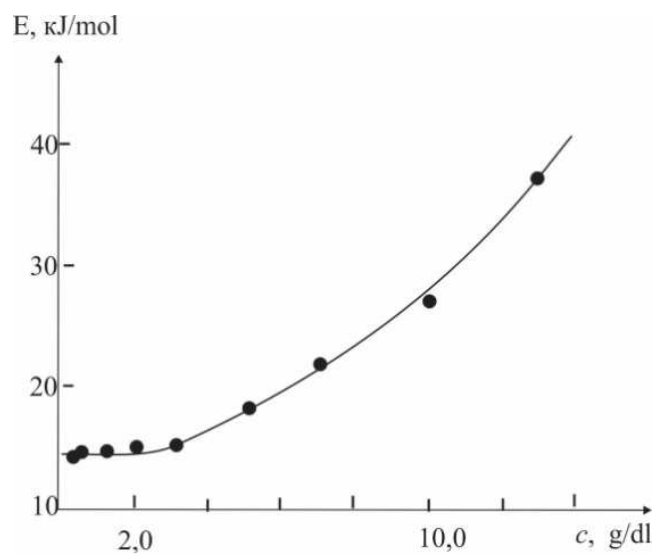

Fig. 3. Dependence of the activation of the viscous flow of pectin solutions on its content in the solution. other polyelectrolytes [19; 23-25].
Thus, all curves shown in fig. 2 characterize the solutions with the concentration greater than the crossover point. But only when the concentration of the polymer in the solution exceeds the value of $C_{e}$, the viscosity curves take the form that pseudoplastic liquids should have.

The formation of fluctuation network of meshes is also reflected in the concentration dependence of the activation energy of viscous flow. In fig. 3 we can see that a kink in the concentration dependence of the activation energy of a viscous flow, indicating a change in the mechanism of mass transfer in a solution, occurs at the values corresponding to the concentration at which the mesh of entanglements is formed. The activating energy values of viscous flow PC are low and in the case of diluted solutions coincide in order of magnitude with the activation energy of the viscous flow of the solvent, which agrees with the experimental data for 
a)

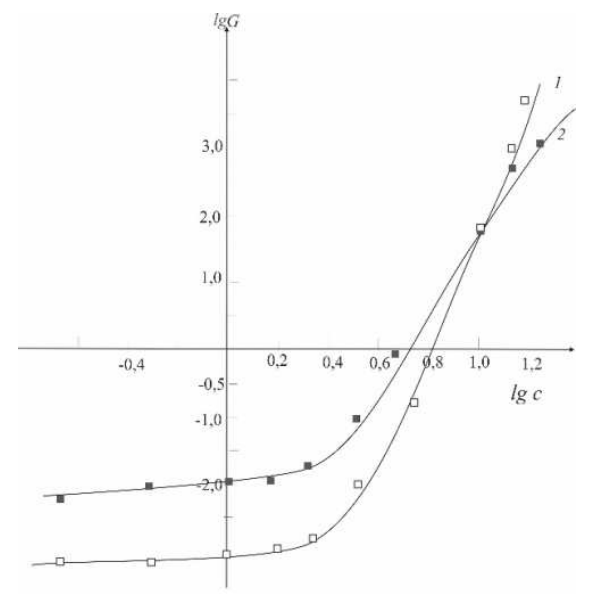

б)

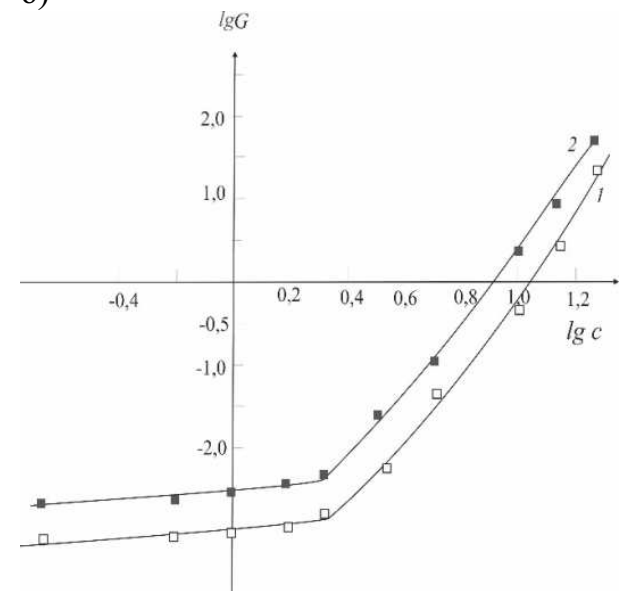

Fig. 4. Dependence of the accumulation modulus (1) and losses (2) for pectin solutions at temperatures of 20 (a) and $80^{\circ} \mathrm{C}$ (b) on its content in the solution.

An examination of the dependences of the accumulation and loss modulus on the concentration of PA in solution also showed that a sharp increase in the values of the accumulation and loss moduli begins in the concentration range of the order of $C_{e}$ (fig. 4).

It can be noted that at temperatures of $15-30{ }^{\circ} \mathrm{C}$, a concentration equal to $10 \mathrm{~g} / \mathrm{dl}$ is determined, at which the storage modulus becomes greater than the loss modulus, i.e. the viscoelastic fluid becomes an elasticviscous body (fig. 4a). In this case, the polymer liquid loses its fluidity. At temperatures of $40-80{ }^{\circ} \mathrm{C}$ in the entire investigated concentration range, the accumulation modulus has lower values than the loss modulus, i.e. PC solution behaves like a viscoelastic fluid (fig. 4b). The difference in the behavior of PS solutions at different temperatures is obviously due to the fact that the number of nodes of the fluctuation network at elevated temperatures is significantly less than at low temperatures.

All in all, our study of PS solutions showed that the polyelectrolyte nature of the polymer introduces significant features into its rheological behavior. These features are manifested in the form of low values of the activation energy of viscous flow, in the absence of an anomaly in the viscous flow of solutions above the crossover point, as well as in the existence of a concentration region in which macromolecules are in contact with each other, but do not form a fluctuation network of meshes.

\section{REFERENCES}

1. De Gennes P. G. Scaling concepts in polymer physics. New York: Cornell University Press, 1979.

2. Malkin A., Isaev A. Pheology: conception, methods, applications. Toronto, Canada: ChemTec Publishing, 2005.

3. Chang Dae Xan. Rheology in polymer processing. New York, San-Francisco, London: Academic press, 1976.

4. Schramm G. A. Practical Approach to Rheology and Rheometry. Karlsruhe, Federal Republic of Germany: Gebrueder HAAKE GmbH, 1998.

5. Doi M., Edwards S. P. Dynamics of concentrated polymer systems. Part 1. Brownian motion in the equilibrium state //
Journal of the Chemical Society, Faraday Transactions 2 . 1978. Vol. 74. No. 10. P. 1789

6. De Gennes P. G. Dynamics of Entangled Polymer Solutions // Macromolecules. 1976. Vol. 9. No. 4. P. 587.

7. Vinogradov G. V., Malkin A. Ya. Rheology of Polymers. Berlin, Heidelberg, New York: Springer-Verlag, 1980. XII. $468 \mathrm{p}$.

8. Klein J. The onset of entangled behavior in semidilute and concentrated polymer solutions // Macromolecules. 1978. Vol. 11. No. 5. P. 852.

9. Farnoux B., Nierlich M., Cotton J. P., Boue F., Daoud M., Jannink G. Observation of the collapse of a polymer chain in poor solvent by small angle neutron scattering // J.Chm.Phys. 1978. Vol. 69. No. 4. P. 1379.

10. Cohen J., Priel Z., Rabin Y. Viscosity of dilute polyelectrolyte solutions // J.Chm.Phys. 1988. Vol. 88. No. 11. P. 7111.

11. Takahashi Y., Iio S., Matsumoto N., Noda I. Viscoelastic properties of polyelectrolyte solutions in nonentangled concentrated regions // Polymer International. 1996. Vol. 40. No. 4. P. 269.

12. Dobrynin A. V., Rubinshtein M., Colby R. H. Scaling theory of polyelectrolyte solutions // Macromolecules. 1995. Vol. 28. No. 6. Pp. 1859-1871.

13. Muthukumar M. Dynamics of polyelectrolyte solutions // J. Chem. Phys. 1997. Vol. 107. No. 7. P. 2619.

14. Laís B. Norcino, Juliano E. de Oliveira, Francys K. V. Moreira, José M. Marconcini, Luiz H. C. Mattoso. Rheological and thermo-mechanical evaluation of bio-based chitosan/pectin blends with tunable ionic cross-linking // International Journal of Biological Macromolecules. 2018. Vol. 118. No. 15 . Pp. 1817-1823.

15. Litmanovich E. A., Orleneva A. P., Korolev B. A., Kasaikin V. A., Kulichikhin V. G. Dynamics of polymer chain in aqueous and salt-containing aqueous solutions of poly (dimethyl diallylammonium chloride) // Polymer Science. Series A. 2000. Vol. 42. No. 6. P. 689.

16. Ovodov Yu. S. Current views on pectin substances // Russian Journal of Bioorganic Chemistry. 200. Vol. 35. No. 3. Pp. 269-284.

17. Markov P. A., Krachkovsky N. S., Popov S. V., Durnev E. A., Martinson E. A., Litvinets S. G. Mechanical properties, structure, bioadhesion, and biocompatibility of pectin hydrogels // Journal of Biomedical Materials Research Part A. 2017. Vol. 105. No. 9. Pp. 2572-2581,

18. Baranov V. G. Brestkin Yu. V., Agranova S. A., Pinkevich V. N. Povedeniye makromolekul polistirola v «zagushchennom» khoroshem rastvoritele // Vysokomolekulyarnyye soyedineniya. Seriya B. 1986. Vol. 28. No 11. Pp. 841-843.

19. Orleneva A. P., Korolev B. A., Litmanovich A. A., Zakharova Yu. A. Features of Rheological Behavior of Aqueous Solu- 
tions of Poly (N,N-dymethydiallylammonium chloride) // Polymer Science. Series A. 1998. Vol. 40. No. 7. Pp. 1179-1186.

20. Litmanovich E. A., Syaduk G. V., Lysenko E. A., Zezin A. B., Kabanov A. V., Kabanov V. A. Effect of concentration regime on rheological properties of sodium polymethacrylate and its complexes with polystyrene-poly (N-ethyl-4-vinylpyridinium bromide) block copolymer in aqueous salt solution // Polymer Science. Series A. 2006. Vol. 48. No. 9. Pp. 997-1003.

21. Dreval' V. E. Vasil'ev G. B., Litmanovich E. A., Kulichikhin V. G. Rheological properties of concentrated aqueous solutions of anionic and cationic polyelectrolyte mixtures // Polymer Science. Series A. 2008. Vol. 50. No. 7. P. 751.

22. Chernova V. V., Valiev D. R., Bazunova M. V., Kulish E. I. Features of the rheological behavior of polymer-colloidal dis- persions based on a sodium salt of carboxymethyl cellulose and silver iodide sols // Russian Journal of Physical Chemistry B. 2018. Vol. 12. No. 4. Pp. 701-708.

23 Bazunova M. V., Valiev D. R, Chernova V. V., Kulish E. I Rheological properties of solutions of chitosan and its complexes with colloid particles of a silver iodide sol // Polymer Science. Series A. 2015. Vol. 57. No. 5. Pp. 675-679.

24. Vikhoreva G. A., Rogovina S. Z., Pchelko O. M., Gal'braikh L. S. The phase state and rheological properties of chitosan-acetic acid-water systems // Polymer Science. Series B. 2001. Vol. 43. No. 6-7. Pp. 166-170.

25. Vinogradov G. V. Critical regimes of deformation of liquid polymeric systems // Rheologica Acta. 1973. Vol. 12. No. 2. Pp. 357-373.

Submitted on 11.02.2021. 